\title{
NUMBER CRUNCHING
}

\section{A Flood Of Unexpected Registrants Inundated Albuquerque, But Organizers Coped And The Spring Meetings Are Well Under Way}

Organizers of the Materials Research Society's inaugural Annual Spring Meeting, held Feb. 27-29 in Albuquerque, New Mexico, had a pleasant surprise: Nearly twice as many people attended as they had expected. "Two overflow hotels, in addition to the Albuquerque Marriott headquarters, had to be conscripted to handle the registrants," notes Gordon Pike, Sandia National Laboratories.

\section{Overwhelming Success}

Pike, who with Ross Lemons, Los Alamos National Laboratories, and Noble Johnson, Xerox Palo Alto Research Center, co-chaired the meeting, terms it an "overwhelming success."

"We made our plans based on estimated attendance of about 300 people," he says. This certainly confirms that the Society's rationale for instituting the Spring Meetings is justified."

In its decade-long existence, the MRS has grown to substantial size, and the rate of growth has accelerated in the past two years. As facilities at the Annual Meeting became inadequate to serve the materials community to the best advantage, the Society committed itself to a second major technical conference annually. The meeting in Albuquerque was the first of these. The 1985 Spring Meeting will be held in April in San Francisco.

\section{Room for Further Growth}

The Spring Meetings provide much-needed room for further growth of the MRS. Between the meetings held in Albuquerque and planned for Boston this November, nearly twice as many topical symposia will be offered in 1984 as in 1983. Symposia can now also be rotated between the two conferences, for a repeat time of 18 months. Other advantages include geographical diversity: With the Annual Meeting traditionally held on the East Coast, Spring Meetings will be held in the West. This is more

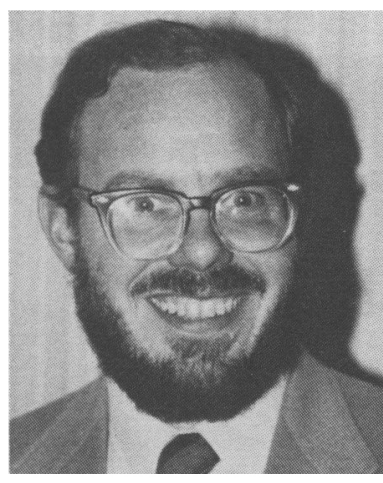

GORDON PIKE economical, for a considerable segment of the MRS membership, and it permits the West Coast meeting to focus on topics of special interest in the Western United States and Asia.

\section{Four Symposia Held}

Pike notes, "The first Spring Meeting comprised four

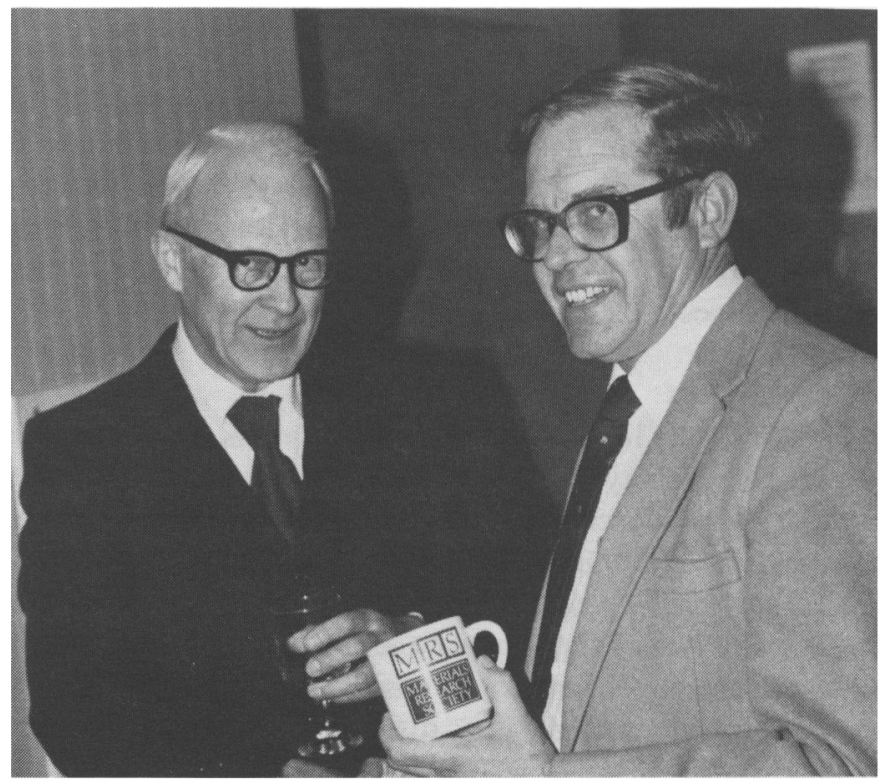

'WOODY' WHITE, MRS President (right), presents a memento of the Society's Spring Meeting in Albuquerque to John Galt, Vice President of Research, Sandia National Laboratories

topical symposia: ceramics, thin film transistors, display and printing materials, and optical and magnetic data storage materials. Each was heavily attended, particularly the 'Better Ceramics Through Chemistry' symposium. This explored new ways of using solution chemistry or pyrolysis techniques to produce fine mono-dispersed powders, gels, ultrapure glasses, and polycrystalline ceramics."

Although the program for the 1985 Spring Meeting is still quite preliminary, a sharply larger number of symposia are expected to be offered, particularly in the light of Albuquerque's success.

\section{Conference Support}

"Local arrangements for the Albuquerque meeting were superbly handled by Rod Quinn of Sandia National Laboratories," Pike reports. "For the first time in the Society's short history, he was assisted by a professional meeting planner, Judith Eagan, from Albuquerque Meeting Service.

"Quinn also had help from MRS Councillor Rod Ewing and Harold Anderson, both from the University of New Mexico, who arranged for the loan of audio-visual equipment and student aides. Altogether there were many people from Sandia Labs and the University of New Mexico involved in running the meeting, and the MRS is grateful to them and their institutions for contributing to this highly successful meeting." 